\title{
Tissue loss in corals infested by acoelomorph flatworms (Waminoa sp.)
}
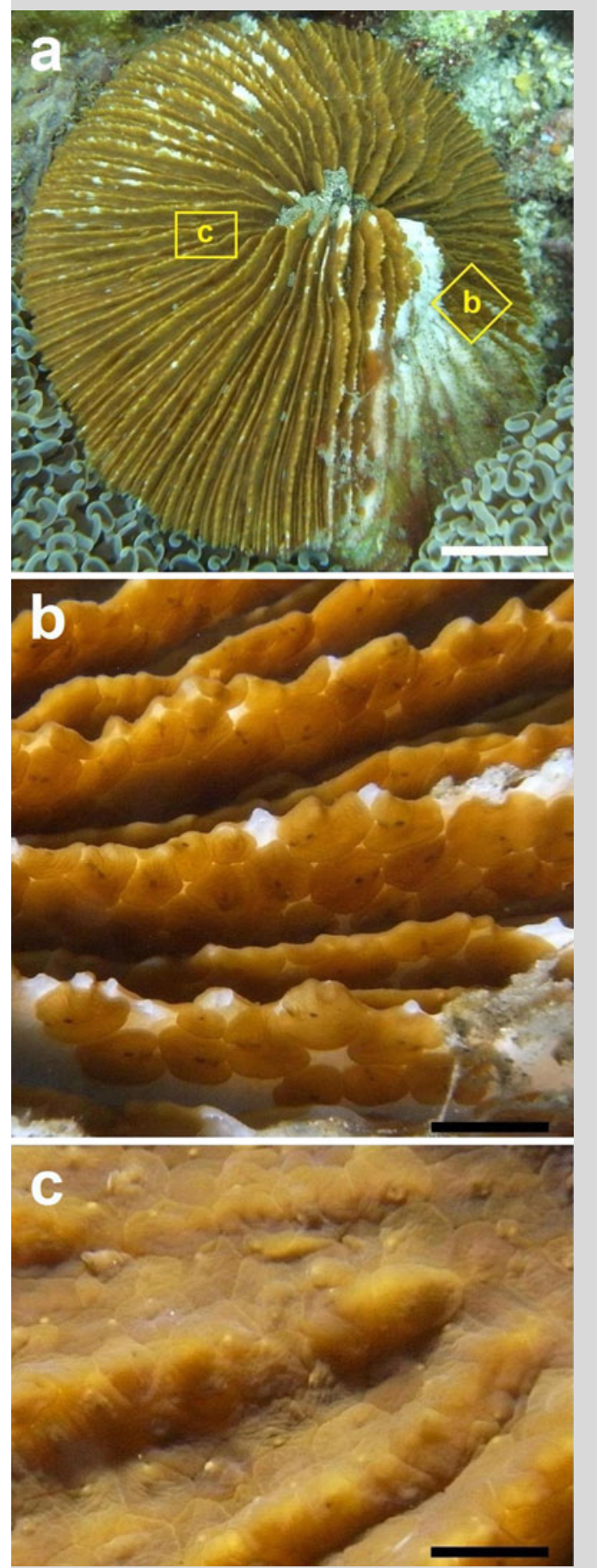

Fig. 1 a Specimen of the mushroom coral Danafungia scruposa showing dense Waminoa cover and tissue loss (squares indicate position of close-ups in $\mathbf{b}$, $\mathbf{c}$; scale bar $2 \mathrm{~cm}$ ). $\mathbf{b}$, $\mathbf{c}$ Close-ups of areas marked in a (scale bars $5 \mathrm{~mm}$ )
Little is known about species and host specificity of epizoic acoelomorphs that live in association with corals (Barneah et al. 2012; Hoeksema et al. 2012). Most records concern zooxanthellate acoels of the genus Waminoa Winsor, 1990, which reproduce both sexually and asexually and may harm their hosts by shading and by eating their protective mucus layer, but no coral injuries have been reported so far (Haapkylä et al. 2009; Naumann et al. 2010).

During a biodiversity survey around Lembeh Island (North Sulawesi, Indonesia) in January-February 2012, various damaged corals were observed that were partly or completely covered by acoels. A specimen of the mushroom coral Danafungia scruposa (Klunzinger, 1879) had $100 \%$ Waminoa cover on its upper surface, except for a part with tissue loss (Fig. 1). Its mouth appeared clogged by sediment (Fig. 1a). The damaged area was not similar to the contact zone with neighbouring corals, although interaction with these corals may have weakened the mushroom coral's defence capacity.

Apparently, acoels can harm corals by smothering them, which may hinder their respiration, feeding and sediment shedding capacities. The infestation may be contagious, since a Sandalolitha robusta (Quelch, 1886) mushroom coral, with more than $90 \%$ acoel cover was observed to be in close contact with one of another species, Pleuractis granulosa (Klunzinger, 1879), that was only infested at the nearest side, implying that acoels crawled or swam from one coral to another. All presently reported mushroom coral species represent new host records for Waminoa (see Hoeksema et al. 2012).

Acknowledgments Observations took place during a Marine Biodiversity Workshop based at the Bitung Field Station, Research Centre for Oceanography (RCO), Indonesian Institute of Science (LIPI).

Open Access This article is distributed under the terms of the Creative Commons Attribution License which permits any use, distribution, and reproduction in any medium, provided the original author(s) and the source are credited.

\section{References}

Barneah O, Ben-Dov E, Benayahu Y, Brickner I, Kushmaro A (2012) Molecular diversity and specificity of acoel worms associated with corals in the Gulf of Eilat (Red Sea). Aquat Biol 14:277-281

Haapkylä J, Seymour AS, Barneah O, Brickner I, Hennige S, Suggett D, Smith D (2009) Association of Waminoa sp. (Acoela) with corals in the Wakatobi Marine Park, South-East Sulawesi. Indonesia. Mar Biol 156:1021-1027

Hoeksema BW, van der Meij SET, Fransen CHJM (2012) The mushroom coral as a habitat. J Mar Biol Assoc UK 92:647-663

Naumann MS, Mayr C, Struck U, Wild C (2010) Coral mucus stable isotope composition and labeling: experimental evidence for mucus uptake by epizoic acoelomorph worms. Mar Biol 157:2521-2531

B. W. Hoeksema $(\bowtie) \cdot$ Z. T. Farenzena

Department of Marine Zoology, Netherlands Centre for Biodiversity Naturalis, P.O. Box 9517, 2300 RA Leiden, The Netherlands

e-mail: bert.hoeksema@ncbnaturalis.nl

\section{Z. T. Farenzena}

Institute for Biodiversity and Ecosystem Dynamics, University of Amsterdam, P.O. Box 94240, 1090 GE Amsterdam, The Netherlands 